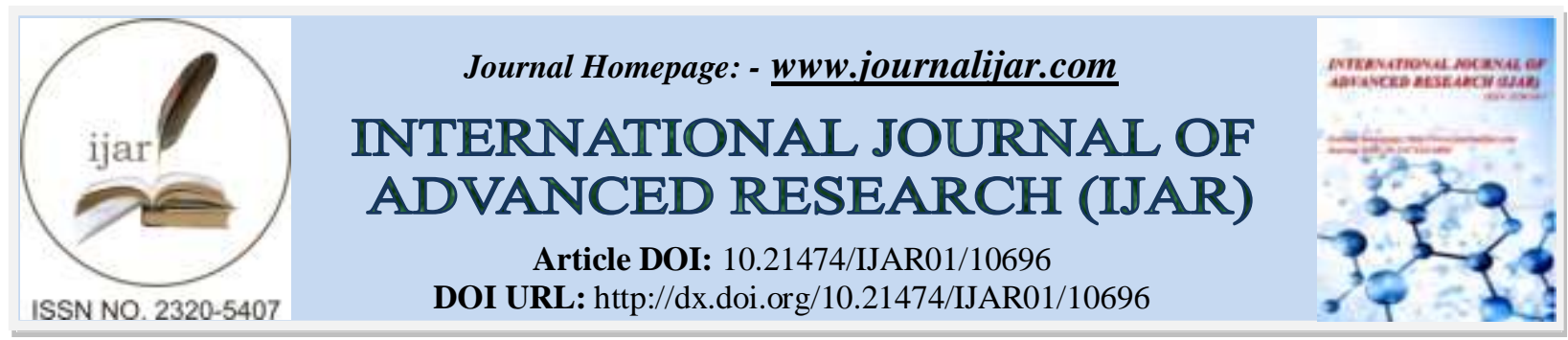

RESEARCH ARTICLE

\title{
TEACHER PERFORMANCE INFLUENCERS - A MULTI-NATION COMPARISON
}

\section{Gowri Menon}

Symbiosis International (Deemed University).

\section{Manuscript Info}

\section{Manuscript History}

Final Accepted: 22 February 2020

Published: March 2020

Key words:-

Higher Education, Performance, Performance Influencer, Performance Management, Teacher
Received: 20 January 2020

\begin{abstract}
Teachers are an integral part of society, and handhold future generations into becoming able citizens for tomorrow. They infuse fresh thoughts and actions into society through the youth they educate. Nobility of the profession apart, this is one requiring selfless effort, at not just imparting curriculum to students, but moulding their character as well. With these herculean targets and responsibilities lined up for teachers, the question in focus is whether the systems of performance management they are subject to, is efficient enough to motivate them to put their best foot forward. Performance management starts with performance goal setting, and works its way through execution, assessment, performance reviews and goal revisit. Universities following an agency model of operation rather than stewardship model seldom focus on teacher development and performance improvement. This paper seeks to question only factors that affect the teacher's performance at Higher Educational Institutions (HEIs). Comparisons drawn across teacher performance management systems (PMS) of HEIs in different countries will help us understand the performance and its management in varsities, and track down similarities and differences in factors if any, in the Indian counterpart. The objective is to scrutinize teachers' performance\& PMS and check scope for betterment of the same. Primary data has been obtained from teachers and Heads of 15 colleges affiliated to an Asian University. The paper draws upon secondary data accessed from trusted sources.
\end{abstract}

Copy Right, IJAR, 2020,. All rights reserved.

\section{Introduction:-}

The future of the world lies in the hands of the youth. They are the future managers, entrepreneurs and most importantly the community that elect the people to positions of political power with capabilities to make or ruin a nation. The process of education, knowledge creation and dissemination, facilitating thought and creativity is one of significance. In the early years of one's life the parents can play a major role in teaching the value systems and basic etiquettes. Around 20 early years of one's life is spent acquiring this knowledge from his teachers. The primary and secondary school education, are undoubtedly tough, chiefly due to students' exposure to totally new facts of life, the nuances that one was never aware of; a journey from the unknown to the known. The comprehension of new theories, facts, acquisition of new knowledge was cumbersome and stressful, but less challenging. The students who are now in their infancy and early teens, are lively with the curiosity for new intellect, and patiently and passionately learn from their teachers, almost unquestioningly. When enrolled at HEIs, as young adults, these students feel in control of their lives, become very demanding, and question every practice that they encounter. While it is always 
good to keep the curious child in you awake and enkindle the passionate questioning of the unknown, the attitude is not always this appropriate. They have already learnt the basics of knowledge, identified their rights and wrongs, have formed firm opinions in certain issues in light of their understanding, and this may make it difficult to unlearn and relearn things in the wake of new dynamics in society. The teacher at HEIs is instrumental in reasoning out to the students, how things have changed over the years, how an opinion that was once right, no more holds correct, the factors that caused this change, what is the impact of the changes, and how one needs to work keeping in mind these dynamics. The teacher must work patiently and passionately with each student, with the short term motive of imparting quality education and with a vision to build his character for a lifetime.

\section{Review Of Past Works:}

Performance on a job is affected by a multitude of factors. The basic of all is motivation, which has been supported by renowned theories in the earlier section. However, motivation is just one - yet very significant - of the several factors. All of these factors affect the performance of employees in more ways than one can decipher. This study focuses its attention on factors, internal or external to an employee that impacts his performance in a task. Teachers in higher education are also performing a host of assigned responsibilities besides teaching. Representation in clubs and committees, research output, student advice and mentoring, and contribution to academic betterment are some of them. Only those works have been referred here, which directly concern teachers' performance in HEIs.

\section{Factors affecting teachers' performance and PMS:}

Universities play a very vital role in the definition of teachers' roles, and administering means of improving performance. Managing the performance of teachers is the primary prerogative of the University, further cascading to the college and entrusting this responsibility to the authorities holding positions of power therein. Similar to their corporate counterparts, education industry and higher education in particular, also face their share of problems managing their employees' performance. Ranging from individualistic factors like lethargy, to professional factors like pressure to perform; there are a plethora of factors that interact in influencing the performance of teachers. Performance influencers can be broadly classified as being intrinsic or extrinsic in nature. A glimpse of such factors is presented herein.

\section{Intrinsic Factors Affecting Performance:}

Referring to factors internal to oneself, these can be highly subjective or can be the impact of the work environments which play a vital role in deciding the intrinsic behavior in teachers. A recent study in the UK on the performance of teachers in HEIs revealed some interesting findings (Franco-Santos, 2014). It established that performance of educators was largely guided by factors internal to oneself, and extrinsic motivators proved to be trivial in affecting output. The research elaborated those aspects as

1. empowerment in work related decision making,

2. recognition by peers/superiors,

3. high potential for career growth,

4. affable working environments, and

5. adequacy of resources

can work wonders on teachers' motivation and performance level. In addition, timely and relevant feedback was found primary to performance, so long as the focus was long term, as those in academic roles failed to appreciate feedback given with the intention to better performance in short time horizons. It commonly believed that monetary benefits, in terms of salaries, increments and incentives can be a great motivator. It is commonplace for all industries and sectors to adopt this as a tool to drive performance. Nonetheless, contrary to this belief, studies have contended that monetary systems must not be tried in Universities, since they send an erroneous message to educators who are intrinsically motivated to perform their duties.

\section{Extrinsic Factors Affecting Teachers' Performance:}

They may be identified as causes which are outside of an individual but critically impact the performance. This may be understood to consist of environments created in the organization, either due to organizational factors themselves, or due to factors external to the organizational as well, but have a bearing directly or remotely with the employee's deliverables. It may affect the employees in more ways than one. Speaking of teachers within Universities, the common extrinsic factors affecting teacher's performance in HEIs include 


\section{Occupational stress/pressure:}

Occupational pressures may be physical, mental or emotional in nature. From extremely explicit to inadvertently implicit, in several cases the pressure goes noticed or is too widely accepted to demand attention. Amidst myriad factors that seem to play subtle roles in determining performance, is work environment and organizational mission. Decramer, A. et al (2012) in his recent study conducted on staff employed in Dutch University, on the role played by institutional pressure on performance, identified that the extent of Government funding to a University compelled the latter devote time and attention to fulfil the Government priorities, irrespective of teachers' inclination, interest or motivation. Government had prioritized research output. Universities strategically complied with this requirement by designing a PMS which laid high emphasis on research scores and ratings. This in turn, forced teachers at HEIs to deliver research outcomes expected. They were soon out of their comfort zone, devoting too much time and attention to research, at the cost of their primary duties. This is the case in most nations that are excessively dependant on Government funding for their functional requirements.

Similar were the findings of an extensive survey undertaken in Australia. The teachers of 17 Australian Universities were surveyed on their work climate, and the study revealed that occupational stress in academics was very high. Educators in around $90 \%$ of the cases suffered from very high levels of stress and anxiety, and consequent health disorders. When probed deeper, the teachers mentioned that this stress was primarily on account of administrative responsibilities they had to undertake and societal contributions they were required to make, in addition to teaching. (Winefield, A.H., et al., 2003).

Another researcher (Smithers, 2003), who worked broadly in the space of higher education and occupational stress, disclosed through his study, the results of a survey conducted by the UK based Association of University Teachers which elicited information from over 1,72,000 teachers. The study indicated that 9 out of 10 teachers suffered from work related stress, and among these, more than 6 out of 10, from excessive tension. In addition, 27\% of those who were approached for information thought of 'fairly seriously' considering a change in career, around $50 \%$ of them admitted to have suffered a burnout, more than $70 \%$ were dissatisfied with salary packages and not less than $85 \%$ considered their workload to be too heavy.

Institutional stress has been an area much researched upon (Thorsen, 1996; Tytherleigh et al., 2005; Woods, 2010), and most of them attribute organizational stress to be related to one of the two causes: either the factors in the work environment or the performance management systems themselves causing the pressure to perform. Additionally identified is that University staff constantly encountering psychological stress (Fisher, 1994); and working in evening hours and weekends (Kinman, 1998) had become routine.

Factors Determining Teachers' PMS:

Performance is affected by one's motivation to perform, either the due to internal drive or through external carrot and stick approaches of the organization. Teachers also assume their responsibilities with varying levels of intrinsic and extrinsic motivation. The HEI can be instrumental in initiating and operating a PMS which will enable teachers to perform at their optimum capabilities. Discussed in further sections are factors that influence the design and focus of HEI PMS and the impact of such strategies.

\section{League tables:}

Of increasing relevance to the understanding teachers' performance in Universities is the part played by national and international ranking lists of Universities, otherwise known as 'league tables'. Several studies have disclosed a strong influence of teaching and research performance on the position that Universities adorn in such rank lists (Adler and Harzing, 2008; Brooks, 2005; Dill and Soo, 2005). Such rankings are of extreme significance, and every movement either way in the league table is noticed. These rankings speak volumes about the immense competition among universities nationally as well as internationally. The current era accords a lot of importance to such rankings, which drives them to meticulously manage the performance of their academic departments and teachers. As a consequence, teachers are required to actively engage and perform in those areas of contribution, which move them to the top of the league table.

(iii) Focus on Individual PMS (tangible and intangible)

Of rising importance is the need to focus on individual performance management (IPM) of educators in HEIs. There was an intriguing study conducted almost a decade ago, the detailed report and findings of which was submitted to the European Higher Education Society (Decramer, A., Christiaens, J., \& Vanderstraeten A., 2007). After 
empathizing with the unfortunate state of performance management in HEIs, which focused on a blind race of numbers and ambiguous quantification of achievements, they were enlightened. They ventured a possibility of the extent to which teachers in HEI could use some type of task definition, target setting, monitoring and measurements as well as appraisals, for managing their individual performances (IPMS). The investigation revealed that the current need was for a more comprehensive PMS coupled with IPMS which threw light not only on outputs and outcomes (quantities and numbers) but also on inputs (behaviors adopted in achieving the results/outcomes). The research engraved a new dimension to educator PM which considered individual intangibles like behaviors and traits to be important determinants of performance. While the importance of results was not undermined, they upheld that the means to achieve the end must also be paid attention to. Guest (1997) in his study presented a view which stressed that employees in Universities determine the performances portrayed in higher education, and it would in the long run provide a competitive advantage along with sustainability. He also remarked that Universities aiming for profit optimization must also, for their own sake, focus on individual PMS.

(iv) Institution specific factors

A more comprehensive study (Simons, 1995) attributed performance management robustness to be a function of various factors extrinsic to the educator. He presented a wider perspective of teacher performance management. The study concluded that several factors could have direct and indirect impacts on performance. Among others, he found that

establishment tenure of the HEI;

their primary orientation - whether teaching, research or both;

its operational fund source - whether government aided or self-financed; and

the dimension of the HEI quantified in terms of number of students and employees ;

form reasonable basis to formulate and gauge the effectiveness of a PMS adopted. Studies (Otley 1978 \& Hopwood, 1972) found that employees are thoroughly impacted by the way in which their performance information is used, and the budgets allocated for their increments and incentives can play a key role in determining the motivation and stress levels of employees.

Students' perceptions of teaching \& recall factor

In his seminal work, Murphy, Kevin R. et al. (1986), probed into the students' aspect, as a major stakeholder and determinant of performance ratings. He carried out his investigation through the study of 183 undergraduates. This was an experimental study, wherein the students were divided into two groups. Initially they were both subject to an average lecture. Thereafter, one group was shown two good lectures, and the other group was shown two poor lectures. It was seen that the first group rated the average lecture more positively than the second group. It was an indication that subsequent performances tend to have an effect on the rating of a previous performance. In an actual scenario, it tends to designate that ratings on a performance completed during a review period are likely to be influenced by subsequent performances showcased after the review period. This is more likely when the time lapse between performance and ratings are fairly large so as to permit subsequent performances to intervene in the ratings due to human recall factor. It would be interesting to note that there are several HEIs that allow students to evaluate their teachers on various parameters and some even use student outcomes to measure teacher performance. These feedback and ratings must be taken with a pinch of salt. Not always do 360 degree appraisals promise a more accurate holistic rating; notwithstanding the fact that all stakeholders must be an integral part of the appraisal process. 


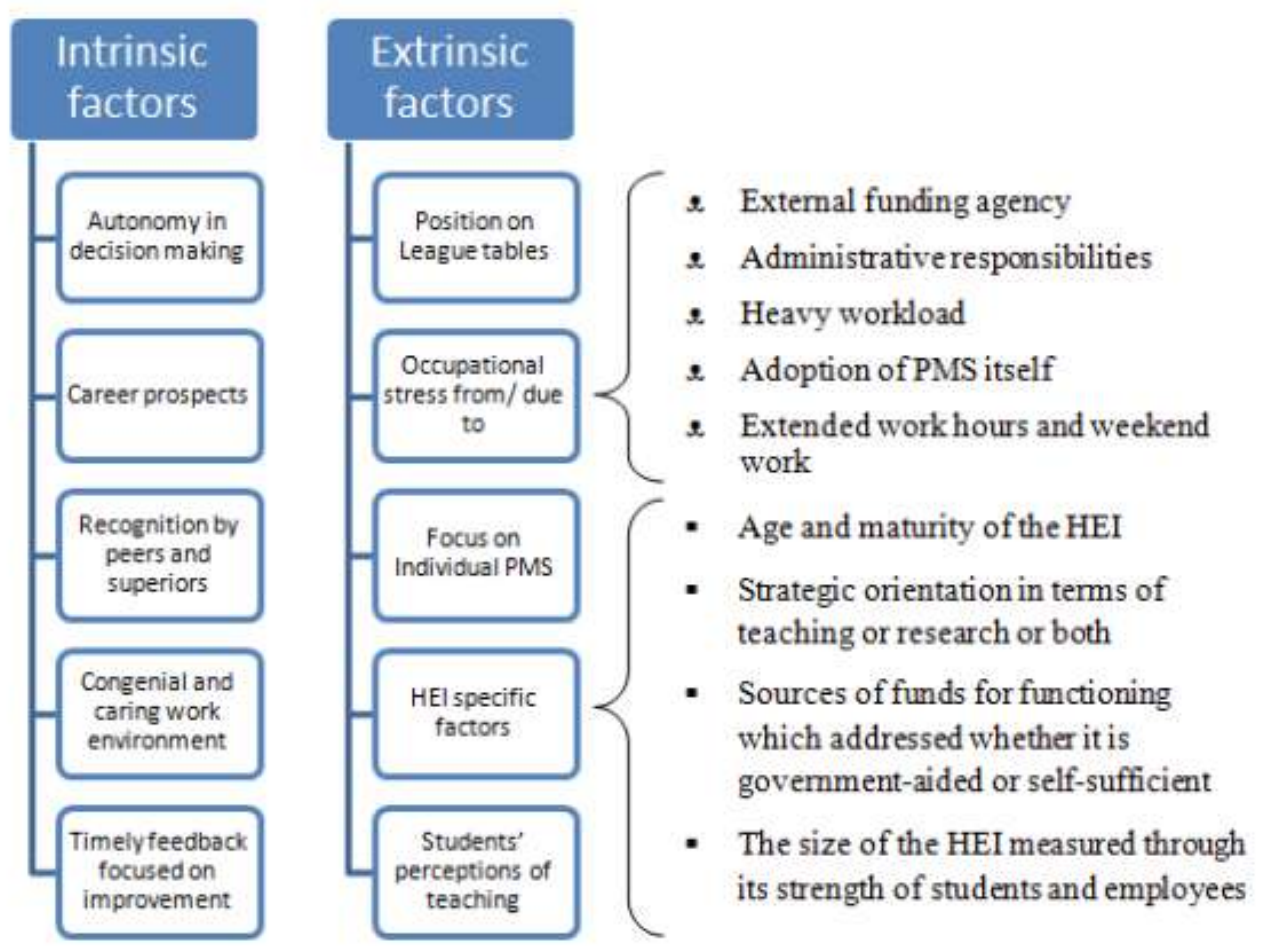

Figure 1:- Factors influencing teacher's performance and PMS.

\section{Research Methodology And Objectives:-}

This empirical study is a move to understand aspects related to teachers' performance. It studies the motives behind performance and the factors impacting the management of teachers' performance and performance ratings, in HEIs. Primary data has been collected from 90 senior faculty members of 15 HEIs affiliated to an Indian University. These HEIs are homogeneous in nature (Menon, G. 2018) as far as their governing policies and functional norms are concerned. They are guided by the principles of the University Grants Commission (UGC), the apex higher educational authority in the country. Secondary data has been obtained from premium research studies on teachers' performance management, conducted world over, and published in elite journals of international repute. The objectives of the study are;

1. To understand the nature of the teachers' job

2. To scrutinize motives for teachers' performance

3. To identify factors impacting teacher PMS and related ratings

4. To check the similarities/differences between Indian Universities and their international counterparts, as far as teacher PM is concerned.

\section{Expectations from Teachers:}

A teacher, these days, is expected to be more than just a teacher, imparting new knowledge to students. One is expected to be a facilitator, mentor, counselor, philosopher, guide, advisor, researcher, and much more. Having a multi-faceted role to play, multi-tasking at almost all times, yet clarity in job profile quite vague, the teacher is found very often juggling between responsibilities (Menon, G. 2017). The performance yardsticks are high, and thus performance is critical. What needs probing at this stage is whether the performance of teachers is managed in an optimal fashion to bring out the best in all these roles so as to meet the expectation; or whether there is opportunity enough for teachers to set the expectation right, and to choose which among these roles one wishes to perform.

\section{Performance motivation theories:}

Performance of tasks and the levels of achievements therein are affected by a plethora of reasons. The topper of the list is motivation. Motivation and its impact on performance, has been an area of interest to researchers for over a century. They have worked on areas such as what is motivation, is it different and unique to each one, can motivation be measured, is motivation intrinsic or extrinsic, are there universal motivators, what are the factors that 
drive motivation, how does motivation affect performance, and the list continues. There have been several models and theories which establish beyond doubt the positive correlation between motivation and performance. Some of them link directly to motivation, while others relate remotely, as they contain within themselves, elements that key to motivation. Besides motivation, the nature of targets to be achieved, determination, expectation, etc are a few other factors impacting performance. Some noteworthy theories in this respect are

Maslow Need hierarchy theory: Abraham Maslow stated that people are motivated by needs that follow a particular order or hierarchy. Unless lower order needs are satisfied, the higher order needs don't emerge. When higher order needs are prioritized and lower order needs compromised, it retards motivation, and adversely impacts performance. Other theories on performance which are equally effective and worth mentioning in this context are Self determination theory, justice theory, goal-setting theory, control theory, social cognitive theory, and stewardship Vs. agency theory.

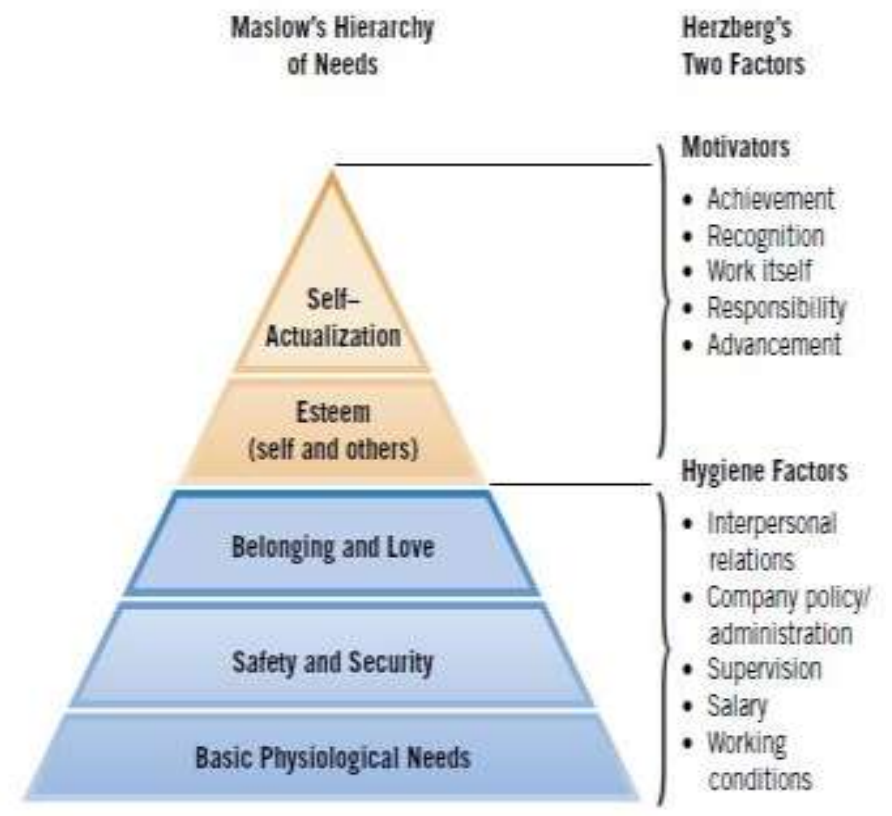

Figure 2:- Maslow's Need hierarchy \& Herzberg's Theory.

Herzberg's Hygiene-motivation theory: Also known as dual factor theory, it states that there are certain factors in the workplace that cause job satisfaction, while a separate set of factors cause dissatisfaction. It is important to attend to the satisfiers and remove causes of dissatisfaction.

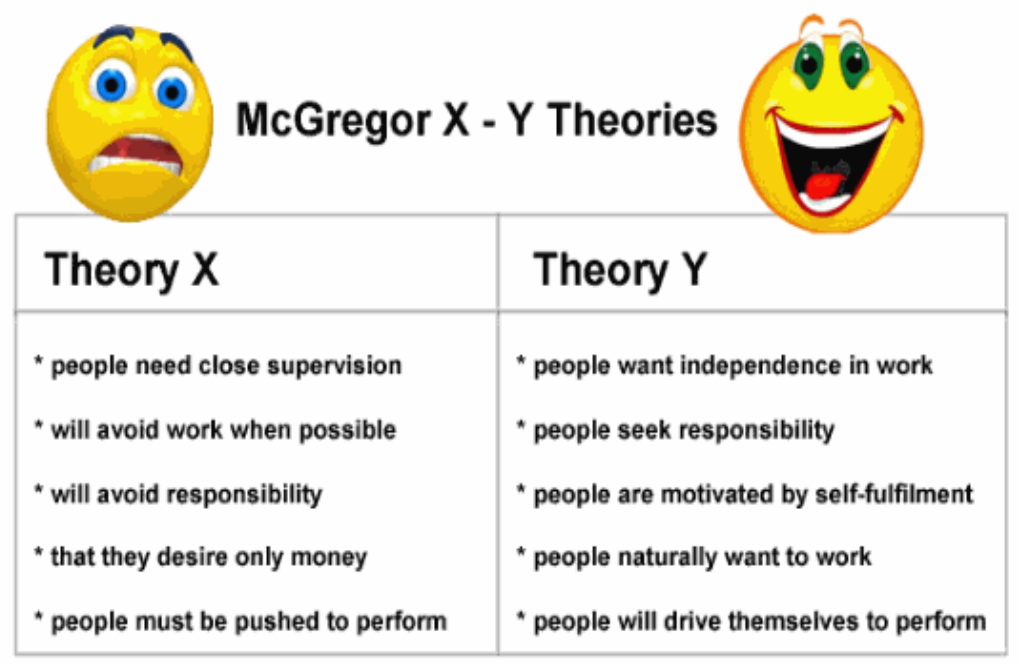

Figure 3:- McGregor's X \& Y Theory of motivation. 
McGregor's $\mathrm{X}$ and $\mathrm{Y}$ theory: two contrasting models of workforce motivation applied by managers in human resource management. It identified that man is inherently of two types; $\mathrm{X}$ type (unenthusiastic, lazy and lacking initiative) and $\mathrm{Y}$ type (enthusiastic, seeking responsibility and taking initiative). Managing work with Theory $\mathrm{X}$ mechanism while employees belong to Theory Y and vice versa; can be a disaster.

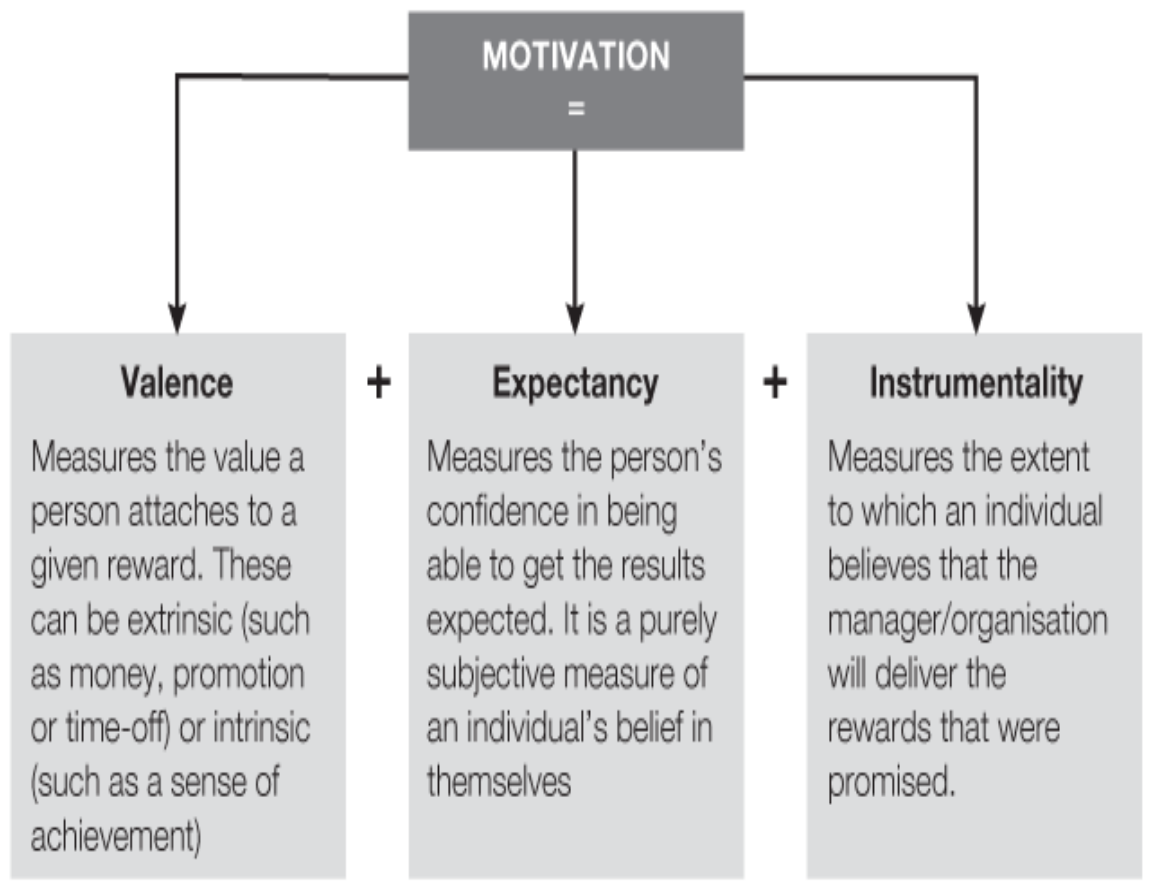

Figure 4:- Victor Vroom's Expectancy theory.

Vroom's Expectancy theory: The theory voiced that behavior results from conscious choices among alternatives whose purpose it is to maximize pleasure and to minimize pain. As such, it is largely dependent on individual interests, traits, personality, skill, knowledge, etc. Where individual aspects are disregarded, performance is not managed at its best.

\section{Analysis Of Responses:}

The teachers were questioned about the aspects relating to intrinsic motivation to work, workload, occupational pressure, administrative duties, and performance management effort by the HEI. The heads of the institutions were approached for information on significance of league tables, HEI aspects, administration practices of teacher PMS and individual PMS focus. Primary data recorded through student feedback forms and supported by observation, were the means to obtain information with respect to student perception of teaching and recall factor. A total of 150 students' feedback forms, averaging 10 per institution, were considered towards this purpose. Observation of the teaching performance of teachers - for whom student feedback was factored - was undertaken longitudinally on three occasions over a period of 1 year.

The tabulation below is representative of the primary data collected on the various aspects relative to teachers' performance management. Table 1 shows teacher responses gathered through a structured questionnaire. Thereafter, the employer perspective was captured through responses from Heads of HEIs gathered in an interview schedule and finally student perception was gauged. These were the three important stakeholders considered for this study. All questions asked for the study, were closed ended, on a 5 point likert scale, with 5 indicating highest level (of satisfaction/motivation) and 1 for the least level. The table is drawn up two dimensionally.

Table 1:- Teacher responses to performance influencers.

\begin{tabular}{|l|l|l|l|l|l|l|}
\hline & $\begin{array}{l}\text { highly satisfied } \\
\text { highest level* }\end{array}$ & $\begin{array}{l}\text { Satisfied/ } \\
\text { high level }\end{array}$ & $\begin{array}{l}\text { Neutral/ } \\
\text { moderate } \\
\text { level }\end{array}$ & $\begin{array}{l}\text { unsatisfied/ } \\
\text { low level }\end{array}$ & $\begin{array}{l}\text { highly } \\
\text { unsatisfied/ } \\
\text { lowest level }\end{array}$ & Total \\
\hline Intrinsic & 40 & 18 & 9 & 11 & 12 & \\
\hline
\end{tabular}




\begin{tabular}{|c|c|c|c|c|c|c|}
\hline motivation*(a) & & & & & & \\
\hline $\begin{array}{l}\text { Teaching } \\
\text { Workload }^{\$}(\mathrm{~b})\end{array}$ & 19 & 33 & 11 & 13 & 14 & 90 \\
\hline $\begin{array}{l}\text { Occupational } \\
\text { comfort }^{\$}(\mathrm{c})\end{array}$ & 12 & 14 & 9 & 28 & 27 & 90 \\
\hline $\begin{array}{ll}\text { Roles }_{\text {package }^{\$}}(\mathrm{~d}) & \text { Pay }\end{array}$ & 6 & 11 & 20 & 18 & 35 & 90 \\
\hline Overall PMS ${ }^{\$}(\mathrm{e})$ & 17 & 14 & 15 & 25 & 19 & 90 \\
\hline Total $(b+c+d+e)$ & 54 & 72 & 55 & 84 & 95 & 360 \\
\hline Total & 126 & & 55 & 179 & & \\
\hline
\end{tabular}

Interpretation: 90 teachers provided their responses on five aspects of their work. A total of $90 * 5=450$ responses were obtained.

The teachers at HEIs within the sample seemed to showcase a high level of intrinsic motivation. This means that their performance is largely guarded by their personal motivation to do well. 58 of the 90 teachers expressed an internal motivation to perform. 10\% were unsure of the level of self-motivation and a minority admitted that they did not have a high disposition to complete their tasks to perfection. Intrinsic motivation surges from the scope for career growth, challenge, recognition, leadership and power.

The remaining part of the table is dedicated to factors external to the employee/teacher which influence performance and related ratings. Teachers in the HEIs were requested to indicate satisfaction with factors like teaching workload, occupational comfort, non-teaching duties and the overall PMS. A whopping majority seemed satisfied with their teaching workload. Interestingly, it was found that even where the number of classes and students taught were higher than norms in certain cases, the teachers showed less discontent. They agreed that teaching was their core competency, and hence they enjoyed teaching and interacting with students in class. The tabulation reveals that the number of teachers who were satisfied with their teaching workload was almost twice as much as those who were unsatisfied. Less than $15 \%$ preferred to take a neutral stand. Contrary to their European counterpart, where close to 85\% were unhappy about their workload, the Indian scenario saw teachers, who quite as much have an excessive teaching workload, but accepted and adapted to the situation uncomplainingly. However, similar to the findings of Kinman, 1998 and Fisher, 1994 the teachers in Indian HEIs also admitted to undergoing severe psychological stress due to work expected to be turned out in late evenings and over weekends.

As regards occupational comfort, characterized through conditions in the working environments, targets to achieve, autonomy in decision making, orientation of the institution, etc., teachers vociferously expressed their sorrow with the current system. Around $60 \%$ of the respondents said they were under immense pressure, as a matter of routine. Though the reasons cited for the pressure were dissimilar, they constituted to occupational pressure in one way or the other. Some were pressurized by unrealistic targets to achieve, some stated that the working environment was too harsh, still others complained of micro-management. A few also commented on peer pressure, lack of recognition, lack of transparency, stifling norms, unfriendly employee-related policies, etc. as areas of concern. Almost $1 / 3^{\text {rd }}$ of them found the organizational climate comfortable while 9 of them seemed neither satisfied nor dissatisfied. Occupational pressure, and its impact on teacher performance, is akin to that of UK, with a clear majority of the teachers experiencing moderate to acute work stress, and burnout.

Table 2:- Comparing factors contributing to occupational pressure for teachers in HEIs.

\begin{tabular}{|c|c|}
\hline International & Indian \\
\hline \multicolumn{2}{|c|}{ Differences } \\
\hline Societal contribution (Winefield, A.H., et al., 2003) & Lack of recognition for achievements \\
\hline Heavy workload (Smithers, 2003) & Peer pressure (competitive/non-competitive) \\
\hline Salary package (Smithers, 2003) & Autonomy in decision making/micro management \\
\hline $\begin{array}{l}\text { Work environment, incl. pressure to perform (Thorsen, } \\
\text { 1996; Tytherleigh et al., 2005; Woods, 2010) }\end{array}$ & Stifling norms/unfriendly employee policies \\
\hline $\begin{array}{l}\text { Student perception of teaching \& recall factor (Murphy, } \\
\text { Kevin R. et al., 1986) }\end{array}$ & $\begin{array}{l}\text { Student feedback (jargon, mechanism to capture and } \\
\text { timing) }\end{array}$ \\
\hline \multicolumn{2}{|l|}{ Similarities } \\
\hline Ig Agent & \\
\hline
\end{tabular}


Orientation towards research (at the compromise of teaching)

League tables (the need to make good, factors that matter)

Administrative responsibilities (tasks not challenging to the teacher's profile)

Teachers also seemed worried about roles and responsibilities besides teaching and overall pay package. Invariably all teachers were roped into duties beyond teaching. 19\% of the teachers surveyed were contented at the opportunity to do something other than mediocre teaching, and found it interesting and enriching to engage in such activity. Close to $59 \%$ argued that such responsibilities not only divided their attention to teaching, but also wasn't career enhancing, in the long run. Their contention was that teaching was their primary function, and imposing nonteaching responsibilities was non-democratic and was non-developmental to their career. Around $8 \%$ confessed that even research must be done at the interest of the teacher, as compelled research leads to poor quality research, does not add anything new to the existing body of knowledge, and is a constant source of pressure on teaching performances too! As regards pay package, the teachers maintained that not only were they unattractive, but increased infrequently and unlinked to performance. Factors like seniority of tenure and cadre mattered more than output in deciding the salary and increments.

When questioned about their opinion about the overall satisfaction with the PMS system in place, around 50\% opined that there is ample scope to improve the PMS in design and execution. Approximately $35 \%$ stated that the PMS was satisfactory and $1 / 6^{\text {th }}$ of them were neutral about the efficacy of overall PMS.

Table 3:- Teacher satisfaction with PMS.

\begin{tabular}{|c|c|c|c|c|}
\hline Researcher & Year of publication & $\begin{array}{l}\text { International } \\
\text { (approx. \%) }\end{array}$ & counterpart & $\begin{array}{l}\text { Indian scenario (approx. } \\
\% \text { ) }\end{array}$ \\
\hline \multicolumn{2}{|c|}{ Teaching Workload } & \multicolumn{3}{|c|}{ Satisfaction } \\
\hline Fisher & 1994 & \multirow{2}{*}{\multicolumn{2}{|c|}{15}} & \multirow{2}{*}{57.7} \\
\hline Kinman & 1998 & & & \\
\hline \multicolumn{2}{|c|}{ Occupational comfort } & \multicolumn{3}{|c|}{ Satisfaction } \\
\hline Winefield, A.H., et al. & 2003 & \multirow{2}{*}{\multicolumn{2}{|c|}{10}} & \multirow{2}{*}{28.9} \\
\hline Smithers & 2003 & & & \\
\hline \multicolumn{2}{|c|}{ Roles and Pay package } & \multicolumn{3}{|c|}{ Satisfaction } \\
\hline Thorsen & 1996 & \multirow{4}{*}{\multicolumn{2}{|c|}{30}} & \multirow{4}{*}{18.8} \\
\hline Tytherleigh et al. & 2005 & & & \\
\hline Woods & 2010 & & & \\
\hline Smithers & 2003 & & & \\
\hline Existing Overall PMS & & 18.33 & & 35.13 \\
\hline
\end{tabular}

\section{Interviews of Heads of HEIs:}

When Heads of the HEIs were asked to comment on the PMS they administered in their institutions, they agreed that HEI aspects and funding did have a role to play in deciding the orientation of the PMS for teachers. A fairly newly established HEI, dependant on government funding for operations, is bound to design and carry out a PMS as per the instructions of the governing body. League tables, too, they agreed influenced performance management of teachers. The position on the ranking table, addressing areas of concern and bridging the achievement gaps before next ranking season, were priority and focus areas in arriving at KPAs and targets for teachers to achieve.

Students' voice

Students' perspectives were gauged through their feedback forms on teachers. Since the objective of identifying student perspectives was restricted to understanding their maturity to evaluate their teachers' performance, the feedback of 10 students of the same class on only one teacher for the same subject, was chosen in each HEI. In two colleges there was a large range in evaluation scores offered to teachers. Students who attended classes regularly, and took academics seriously tended to score their teacher more leniently as compared to students who showed up less in class. This did not essentially mean that the teacher was effective or ineffective. It depended more on the frame of mind of the student, his inclination to the course/studies in general and his basic demeanor. These students were scoring their teachers as a mandate, as an activity that must be completed at the end of the semester/year. Being a student enrolled for that course was the only essential qualification for evaluating their teachers. In other colleges the scores were more or less comparable, except for a few parameters; which were worded in a fashion that 
rendered it ambiguous, or liable to multiple interpretations. International studies on students perceptions of teachers and its impact on teacher PMS (Murphy, Kevin R. et al., 1986) also admit that students are an important stakeholder in education, but their evaluations must be handled with a pinch of salt.

When further probed, it was found that some students scored out of compulsion, some others based their evaluations on personal prejudices and few others scored with no objective idea of what a parameter meant. Other interesting revelations made on feedback capturing were that it was

1. Taken at the end of the year/semester - periodic, post-mortem feedback is more judgmental than developmental

2. administered at an inappropriate time - students were asked to evaluate their teachers

3. much after the lectures had concluded and thus scores were based on recall factor

4. during examinations, when they are not in a frame of mind to devote attention to it

5. after the year was over, thus making it too late for any damage control

6. capturing student data - the teacher feedback forms were expressly asking student for their identity, and thus the students refrained from honest and open feedback (in case it was negative)

7. a compulsory forced choice - feedback forms were objective, forced choice based. The ease of analysis was more important than genuine feedback. While narrative and essay evaluations are not encouraged, likert scales may not always be the best option.

8. Multiple factors impacting scores - Students had no idea about the significance of the evaluations they were performing or what would be the consequences. Their scores were influenced by several factors, besides the teaching itself. For eg. Students who were intrinsically motivated to study and seek information, gave more generous scores relative to students who showed little inclination to study.

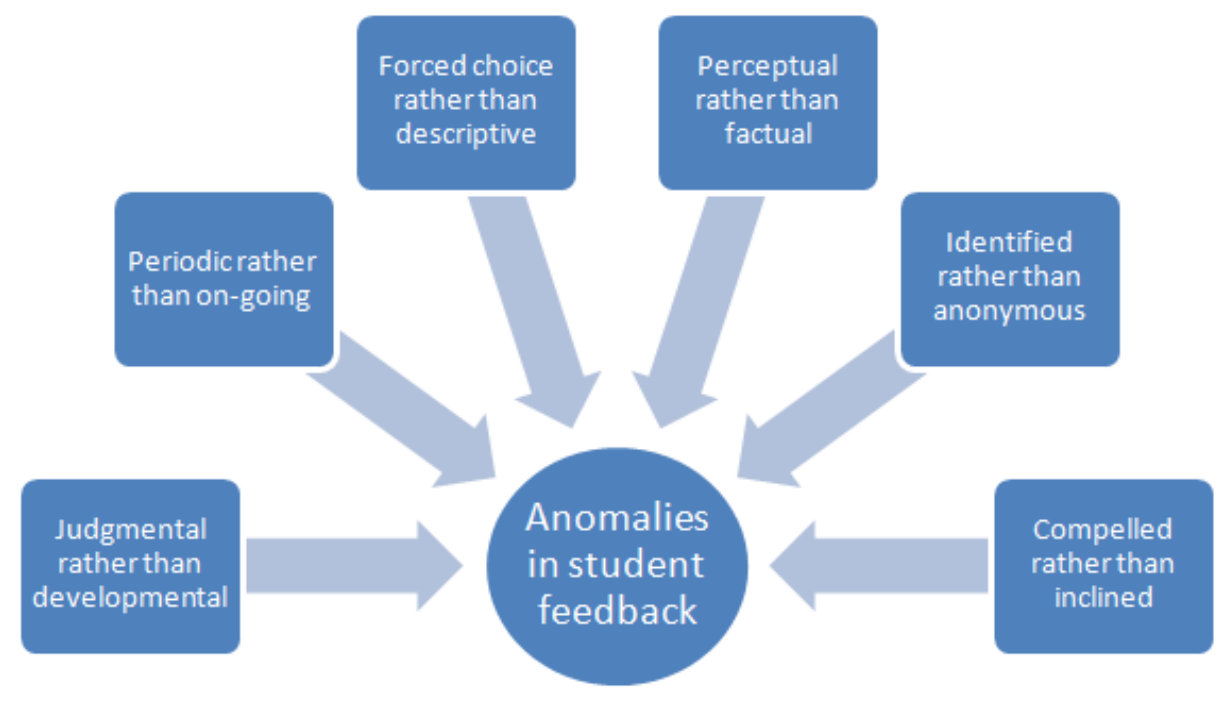

Figure 5:- Anomalies in student feedback.

\section{Findings of the study:}

Teacher performance management is affected by numerous factors, internal and external to the teacher.

Intrinsically motivated teachers are very satisfied with their PMS and complain less. In the Indian scenario around $64 \%$ of the teachers experience a high level of intrinsic motivation which helps them cope with excess work load, salary non-parity, and occupational stress.

Teaching workload is high, as is in the UK, but the views of teachers in both continents are dissimilar. In India, teachers having workloads slightly higher than norms accept and adapt to the requirement. In the UK, there seems to be high level of dissatisfaction with high workloads. As against 15\% teachers who expressed satisfaction with their workload, a majority of Indian teachers seemed contented with close to 58\% contented with the amount of work they are subject to. 
Working beyond office hours and over weekends is resented by teachers in current study, and similar evidences are available in earlier literature.

Occupational pressure does play an important part in influencing performance. Though occupational pressure is a collective term hinting on work environment, expectations, salary, autonomy, leadership, motivation, etc. it is agreed that more than half the teachers in HEIs both in Indian context as well as internationally suffer from reasonably high levels of occupational pressure and burnout. While teachers world over maintain that they are encountering jobrelated tensions, the corresponding levels of stress experienced in global scenario is almost three times that found in India. Interestingly enough, even the causes of occupational stress seem to vary in different geographies.

Non-teaching work is disliked, and demoralizes teachers to a fairly large extent. Teachers do not shy away from work. They are willing to contribute beyond requirement towards their core-competency (teaching) if excused from non-teaching roles and responsibilities.

Similarly salary and performance related incentives affect performances across nations. Literature supports the need to improve compensation packages, and have better job-definition. While a clear minority is satisfied with their roles and payment, a comparison between geographies reveals that only around $2 / 5^{\text {ths }}$ in India are satisfied with their roles and payments. The relative figure in the international HEIs is fairly better at $1 / 3^{\text {rd }}$.

HEIs dependent on Funding from external authorities, are driven by a PMS dictated by the funding agency.

Age of the HEI does not directly impact the teachers' satisfaction with the PMS. HEIs established over half a century back only enjoys the privilege of having emerged out of its teething problems and is able to better focus on planned development. Newer HEIs, on the other hand, have the benefit of setting teachers' performance expectations and initiating a PMS at an early stage.

The student to faculty ratio is also an important factor impacting performance. A small group of students allows for personal attention and thus better performance of a teacher. A teacher managing a large group of students per class is unable to devote individual attention, and this dilutes performance.

League tables are like dormant volcanoes. They do not make themselves very explicit, but are always a hidden agenda in orienting teacher performance in chosen areas.

Students are an important stakeholder in Higher education. Their feedback suffers from certain anomalies and must be corrected.

The PMS, and in general, performance of teachers, globally in impacted by several factors, not all of which are democratic and congenial to the teacher. In such situations, the best of intensions and measures taken by management can prove to be dysfunctional. Teachers internationally are half as satisfied as teachers in India, as regards the overall PMS adopted. This can be largely attributed to their uncomplaining assumption of teaching workload and relatively less levels of stress experienced on the job.

\section{Suggestions:-}

Teachers prepare knowledgeable citizens for the future. They deserve a comfortable working and living environment. Their performance, ratings and institutional PMS is currently influenced by several external factors. Not all of them are non-controllable and dynamic.

Teachers must be prepared to face the queries posed by curious bunch of young adults each day in class. They must be equipped with enough foresight to understand what these queries will be, and then ready the answers for them. Reading not just text books, but newspapers, authentic websites, research papers in the discipline, case studies, are all not just desirable, but essential. Some suggestions for better performance management of teachers may be:

Teachers must be encouraged to teach. They are self-motivated for it. Non-teaching tasks which are technical in nature and career non-enhancing can be handled by administrative staff. 
Occupational stress is a major factor affecting performance. Institutions can take care several of the factors contributing to it, if not all. A conducive working environment, due recognition for achievements, good salary packages and performance linked incentives, autonomy in decision making, interest based research output, are some factors that can be incorporated.

League tables do matter. After it is a snapshot of your expertise vis-à-vis your competitors. However, the institution must never engage in activities and roles with the ranking in mind. With respect to league tables, the following is suggested

1. Roles critical to HEIs must be sincerely pursued, and this must naturally create a desirable position in the rank list. A poor ranking in the past must be analyzed and reasoned, and efforts systematically - not haphazardlyundertaken to build on weak areas.

2. It is suggested that HEIs do not participate in too many surveys aimed at ranking. A single ranking of national repute and one of international character must suffice. Too many surveys, with varying parameters and judging criteria, not only confuse the HEI but also stress the teacher who needs to shift orientation at short intervals of time.

Besides teaching; mentoring, coaching and advisement are areas where the teachers should be roped in most. They are also adept for this due to their proximity to students and by virtue of spending more time with them.

Institutions can begin working on a trend of focusing on individual PMS, where not just output and outcome, but inputs and behaviors are also considered. It calls for a mechanism, where not just the end, but the means to the end are also considered important. This will ensure the sincerity in effort, ethicality in approach and quality in outcome. Funding authorities must not be given the complete authority to modulate teacher PMS. This would result in creation of an agency model driven by profitability, rather than stewardship model built on scholastic merit. If possible their role must be restricted only to talent acquisition - talent management must be the forte of the HEI.

As long as teacher appraisals follow a forced distribution method, aimed at normalcy of result, it seeks to demoralize. Several top notch corporate houses have given up the central tendency approach, with a view to give employees their due.

360 degree appraisals and especially student feedback is indispensible in understanding teacher performance. However, the existing flaws in feedback system must be redressed quickly.

1. Students who have attended a minimum $75 \%$ of the classes must be considered eligible to evaluate the teacher.

2. From the above $75 \%$, students should be encouraged, rather than compelled to evaluate their teachers.

3. Focus must be on the quality of evaluations rather than quantity. A few genuine evaluations are worth more than a truck-load of flawed evaluations.

4. Feedback must be solicited on an ongoing basis, and through multiple channels (not just through feedback forms). Post-mortem feedback is purely judgmental.

5. Feedbacks must be sought at an appropriate time, after a reasonable period of teaching, and when there is still opportunity to improve.

6. Vague terms, semantic errors must be avoided, as far as possible, in feedback

7. Anonymity of student responses must be promised. Students are more comfortable giving feedback (especially negative feedback) when they are not afraid of the consequences that it may attract.

\section{Conclusion:-}

Teachers in Higher educational institutions have a challenging role to play in daily work-life. Better productivity can be expected from them if the PMS is better designed and implemented. The primary areas that require focus are teaching workload, non-teaching responsibilities, occupational comfort characterized through work environments, monetary and non-monetary compensation, safety, career prospects, autonomy in decision making, etc. In addition, student perception capturing in an appropriate fashion can make the evaluation scores more holistic. Funding agencies must exercise more autonomy in infrastructural aspects rather than managing employee performance. In essence, teachers' performance and PMS is affected by a large number of factors, most of which can be regulated at the HEI itself. Attention must be paid to these factors, and addressed relevantly. 


\section{Scope For Future Research:}

Influencers of teacher performance at higher educational institutions have been studied at a broad global level, picking on secondary data from various geographies. Angles such as gender, age, place of origin of teachers have not been considered. Also, a longitudinal study of respondents may have delivered some perspective on true reflections of teachers with respect to their PMS and any changes it underwent. Study of Teacher PMS of selective countries for the sake of comparison with other parts of the globe could throw light on best practices followed by educational institutions embracing win-win situations for stakeholders. These areas open doors for further research on teacher performance influencers on a global scale.

\section{References:-}

1. Adler, N.J. and Harzing, A.W. (2008) 'When Knowledge Wins: Transcending the Sense and Nonsense of Academic Rankings', Academy of Management Learning and Education, 8(1), pp.1-24

2. Brooks, R.L. (2005) 'Measuring University Quality', The Review of Higher Education, 29(1), pp.1-21

3. Decramer, A., Smolders, C., Christiaens, J., \& Vanderstraeten A. (2012), The Impact of Institutional Pressures on Employee Performance Management Systems in Higher Education in the Low Countries, British Journal of Management, 23(51), pp S88-S103

4. Decramer, A., Christiaens, J., \& Vanderstraeten, A. (2007). Individual Performance Management in Higher Education Institutions. Presented at the 29th Annual EAIR Forum

5. Dill, D.D. and Soo, M. (2005) 'Academic Quality, League Tables, and Public Policy: A Cross-National Analysis of University Ranking Systems', Higher Education, 49(4), pp.495-533

6. Fisher, S. (1994). Stress in Academic Life: The Mental Assembly Line. SRHE and Open University Press, Buckingham and Bristol.

7. Francos et al. (2014) 'Performance Management in UK Higher Education Institutions: The Need for a Hybrid Approach', Research and Development series, Cranfield School of Management (Leadership Foundation for Higher Education) Centre for Business Performance

8. Guest, D. E. (1997). Human Resource Management and Performance: A Review and Research Agenda. International Journal of Human Resource Management, 8(3), pp 263-276

9. Hopwood, A.G. (1972) 'An empirical study of the role of accounting data in performance evaluation', Empirical Research in Accounting - Supplement to Journal of Accounting Research, 10(1), pp.156-182

10. Kinman, G. (1998). Pressure Points: A Survey into the Causes and Consequences of Occupational Stress in UK Academic and Related Staff (pp. 1-40). London: Association of University Teachers

11. Menon, G. (2018), Teachers' Performance Management System at Isomorphic Higher Educational Institutions, International Journal of Advanced Research, 6 (3), pp 505-519

12. Menon. G (2017), Critiquing Teacher Performance Management in HEIs: Reviving the Observation Cube, International Journal of Engineering Technology Science and Research, 4(8), pp $492-504$

13. Murphy, K. R., Gannett, B. A., Herr, B. M., \& Chen, J. A. (1986). Effects of Subsequent Performance on Evaluations of Previous Performance. Journal of Applied Psychology, 71(3), pp 427-431

14. Otley, D.T. (1978) 'Budget Use and Managerial Performance', Journal of Accounting Research, 16(1), pp122149

15. Simons, R (1995) Control in an Age of Empowerment, Cambridge, MA: Harvard Business Review, Harvard Business School Press

16. Smithers, R. (2003). Third of Academics Want to Quit. The Guardian available athttps://www.theguardian.com/uk/2003/mar/10/highereducation.lecturerspayaccessed on 1st Dec 2014

17. Thorsen, E.J. (1996) 'Stress in Academe: What bothers professors? Higher Education, 31(4), pp.471-489

18. Tytherleigh*, M. Y., Webb, C., Cooper, C. L., \& Ricketts, C. (2005). Occupational Stress in UK Higher Education Institutions: A Comparative Study of All Staff Categories. Higher Education Research \& Development, 24(1), pp 41-61

19. Winefield, A.H., Gillespie, N., Stough, C., Dua, J., Hapuarachchi, J. and Boyd, C. (2003) 'Occupational Stress in Australian University Staff: Results from a National Survey', International Journal of Stress Management, 10(1), pp.51-63

20. Woods, C. (2010) 'Employee Wellbeing in the Higher Education Workplace: A Role for Emotion Scholarship', Higher Education, 60(2), pp.171-185. 